\title{
As organizações sociais e o contrato de gestão
}

Nina Novaes Coutinho

\section{Resumo}

Este trabalho visa mostrar a importância da Organização Social para o desenvolvimento social. Para tanto, o trabalho apresenta considerações sobre o Estado. Traça linhas gerais sobre o Terceiro Setor, destacando seu conceito e origem. Por fim, as Organizações Sociais e os Contratos de Gestão. $O$ enfoque centraliza-se na Organização Social e sua necessidade nos dias de hoje, mostrando que esta instituição pode ser utilizada para a consecução dos fins sociais de realização dos direitos fundamentais e, assim, alcançar melhorias nas condições de vida dos cidadãos.

Palavras Chave: Estado; Terceiro Setor; Política Estatal; Organizações Sociais; Contratos de Gestão.

\section{Considerações iniciais}

Este artigo busca apresentar a modalidade de parceria entre a Administração Pública e a Organização Social, além de apresentar o instrumento utilizado nessa relação, que é o contrato de gestão. Este é a forma encontrada para o Estado, que busca diminuir suas atribuições, delegar a prestação de serviços públicos a particulares que, neste caso, são as Organizações Sociais.

\section{Estado}

O Estado durante sua evolução passou por vários modelos de organização, dentre os quais pode-se destacar o Estado Totalitário, Liberal, Social e Neoliberal. E foi o Estado Neoliberal que mais contribui para o surgimento das entidades do Terceiro Setor. Isso porque o Estado Neoliberal é o que prega a menor intervenção possível do Estado na vida social, fornecendo ao seu povo somente os serviços essenciais. É nesse momento que surgem as entidades de Terceiro Setor, como uma maneira de suprir a deficiência do Estado. 


\section{Terceiro setor}

É no Terceiro Setor que estão as entidades de direito privado que se propõe, com a iniciativa de pessoas e a constituição de patrimônio, a colaborar com o Estado no desempenho das atividades de interesse público.

No dizer de Maria Sylvia Zanello di Pietro, terceiro setor são "entidades da sociedade civil de fins públicos e não lucrativos." ${ }^{11}$ Para esta autora, Primeiro Setor é o Estado, que com fins públicos desenvolve atividades públicas, ou seja tem por objetivo a consecução do bem comum. O Segundo Setor é a iniciativa privada, o mercado, que com meios privados desempenha atividade privada, visando à circulação de riquezas e o lucro. ${ }^{2}$

O Terceiro Setor usa de recursos privados para exercer atividade de interesse público e tendo como objetivo, somente, o pleno desenvolvimento desta, não visa lucro. 0 seu caráter privado é, principalmente, observado no regime jurídico usado pelas entidades de Terceiro Setor, o qual seja o regime jurídico de Direito Privado, usando parcialmente o de Direito Público.

Citando Cretella Junior, Maria Sylvia Zanello di Pietro explica que as entidades do Terceiro Setor são chamadas de paraestatais, porque atuam ao lado do Estado, ou seja, não visam substitui-lo, mas sim colaborar com este no desempenho de suas atividades. Recebem também a denominação de entidades públicas não estatais, pois, apesar de prestarem serviços de interesse público, não integram a Administração Pública. ${ }^{3}$

Apesar de serem entidades privadas, podem receber certa ajuda do Estado. São requisitos para isso o desenvolvimento de atividade de interesse público (a atividade desempenhada pelo Terceiro Setor deve interessar a toda a sociedade, toda ela pode usufruir deste serviço) e o recebimento de um título jurídico (utilidade pública, fins filantrópicos ou organização social) concedido pelo próprio Estado. ${ }^{4}$

A principal medida de incentivo ao Terceiro Setor foi o Plano Diretor da Reforma do Estado, realizada na década de noventa. Através desta reforma o Poder Público procurou diminuir sua atuação nas atividades econômicas e nos serviços públicos.

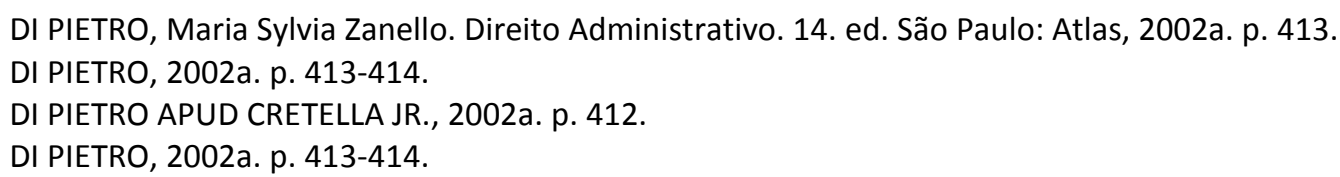


Ao Terceiro Setor importa os serviços não exclusivos, porque a partir desta reforma o Estado passou a delegar estas atividades às entidades do Terceiro Setor. Portanto, pode-se dizer que o crescimento do Terceiro Setor ocorreu com o Plano de Reforma.

O Terceiro Setor divide-se em Organizações Sociais e Organizações da Sociedade Civil de Interesse Público. Estas se caracterizam por serem entes que desempenham atividades de importância social, tais como combate à pobreza, assistência social, promoção da saúde, da cultura e da cidadania. E as Organizações Sociais são definidas como entidades sem fins lucrativos que desenvolvem atividades relacionadas ao ensino, à pesquisa científica, ao desenvolvimento tecnológico, ao meio ambiente, à cultura e à saúde.

\section{Organização social}

O foco deste artigo é a Organização Social, que é uma entidade do Terceiro Setor, ou seja de direito privado, que recebe este título da própria Administração e é autorizada a com ela celebrar contratos de gestão.

Lúcia Valle Figueiredo conceitua:

as organizações sociais são pessoas jurídicas privadas, sem fins lucrativos, cujas atividades, no âmbito federal, são dirigidas ao ensino, à pesquisa científica, ao desenvolvimento tecnológico, à proteção e preservação do meio ambiente, à cultura e à saúde, atendido os requisitos previstos na Lei $9637 / 98 .^{5}$

Expõe a administrativista que as Organizações Sociais não fazem parte da Administração Pública porque, como expresso em seu conceito, tratam-se de pessoas jurídicas de direito privado, ou seja são "organizações particulares". 6

Maria Sylvia Zanello di Pietro entende que as Organizações Sociais:

são pessoas jurídicas de direito privado, sem fins lucrativos, instituídas por iniciativa de particulares, para desempenhar serviços sociais não exclusivos do Estado, com incentivo e fiscalização pelo Poder Público, mediante vínculo jurídico instituído por meio de contrato de gestão. ${ }^{7}$

\footnotetext{
FIGUEIREDO, Lúcia Valle. Curso de Direito Administrativo. 7. ed. São Paulo: Malheiros, 2003. p. 153-154.

FIGUEIREDO, 2003. p. 154.

DI PIETRO, 2002a. p. 419.
} 
Silvio Luis Ferreira da Rocha entende que a Organização Social foi criada para receber do Estado serviços públicos por ele prestados, tais como saúde, educação, cultura e pesquisa científica. ${ }^{8}$ Destaca que, além dos serviços públicos, essas entidades podem prestar atividades socialmente relevantes, que não sejam competência exclusiva do Estado, quando serão por este incentivadas. ${ }^{9}$

Pode-se destacar como suas principais características: descentralização, reversão do patrimônio público, finalidade não lucrativa, autonomia administrativa, fomento pelo Estado, controle social, empregados contratados pelo regime da CLT e parceria com o Estado através do contrato de gestão. ${ }^{10}$

Através das Organizações Sociais, o Estado pretende redimensionar o seu tamanho, permitindo maior participação das iniciativas da sociedade civil, descentralizando seu poder e tornando-se mais eficiente, além de reduzir seus custos. Portanto, a atividade desempenhada pela Organização Social deve ser feita com ênfase ao cidadão, que necessita da prestação deste serviço, e de forma clara, transparente e objetiva.

Deve a Organização Social, por meio de suas atividades, buscar fins de natureza social, que são "aqueles cuja consecução não ocorre no interesse exclusivo ou principal dos membros da pessoa jurídica, como a busca do lucro, mas no interesse comum de toda a coletividade, ou, ao menos, no interesse comum de parte considerável. Expõe a administrativista que as Organizações Sociais não fazem parte da Administração Pública porque, como expresso em seu conceito, tratam-se de pessoas jurídicas de direito privado, ou seja são "organizações particulares". ${ }^{11}$

Silvio Luis Ferreira da Rocha entende que a Organização Social foi criada para receber do Estado serviços públicos por ele prestados, tais como saúde, educação, cultura e pesquisa científica. ${ }^{12}$ Destaca que, além dos serviços públicos, essas entidades podem prestar atividades socialmente relevantes, que não sejam competência exclusiva do Estado, quando serão por este incentivadas. ${ }^{13}$

\footnotetext{
ROCHA, Silvio Luis da. Terceiro Setor. São Paulo: Malheiros, 2003. p. 84. Idem. p 85.

BRITO. Frederico Durão. Reinventando as Instituições. In Revista do Ministério da Administração Federal e Reforma do Estado, no01, maio /98, p. 14-21.

11 BRITO, 1998. p. 15.

ROCHA, 2003. p.84.

Idem. p. 85.
} 
Pode-se destacar como suas principais características: descentralização, reversão do patrimônio público, finalidade não lucrativa, autonomia administrativa, fomento pelo Estado, controle social, empregados contratados pelo regime da CLT e parceria com o Estado através do contrato de gestão. ${ }^{14}$

Através das Organizações Sociais, o Estado pretende redimensionar o seu tamanho, permitindo maior participação das iniciativas da sociedade civil, descentralizando seu poder e tornando-se mais eficiente, além de reduzir seus custos. Portanto, a atividade desempenhada pela Organização Social deve ser feita com ênfase ao cidadão, que necessita da prestação deste serviço, e de forma clara, transparente e objetiva.

Deve a Organização Social, por meio de suas atividades, buscar fins de natureza social, que são "aqueles cuja consecução não ocorre no interesse exclusivo ou principal dos membros da pessoa jurídica, como a busca do lucro, mas no interesse comum de toda a coletividade, ou, ao menos, no interesse comum de parte considerável desta." ${ }^{15}$

Os objetivos de natureza social das Organizações Sociais vêm elencados na Lei 9.637/98 e, portanto, trata-se de rol taxativo, ou seja, que não admite ampliação. São eles: ensino, que é todo conhecimento necessário ao desenvolvimento pleno da pessoa, no que diz respeito a sua cidadania e ao trabalho; pesquisa científica e desenvolvimento

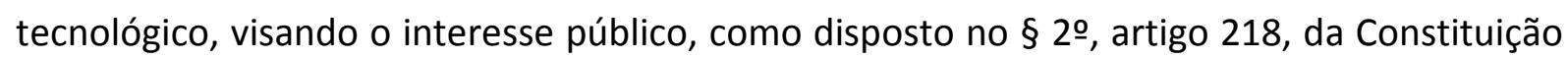
Federal, que requer seja a pesquisa voltada para a solução de problemas brasileiros e para o desenvolvimento regional e nacional; preservação do meio ambiente, ou seja atividades que busquem a manutenção de toda a fauna, flora e ambientes onde se desenvolva vida de qualquer espécie; cultura, seja difundindo ou defendendo valores culturais brasileiros ou que participaram da formação da cultura nacional; e saúde, atividade de prevenção, de cura e de restauração, e desenvolvida nos termos do artigo 196, da Constituição Federal.

Com relação à competência legislativa, União, Estados e Municípios podem legislar a respeito das Organizações Sociais, devendo, entretanto, ser respeitado o campo de atuação entre cada um destes entes. ${ }^{16}$ Já que, como explica Hely Lopes Meirelles, a Lei

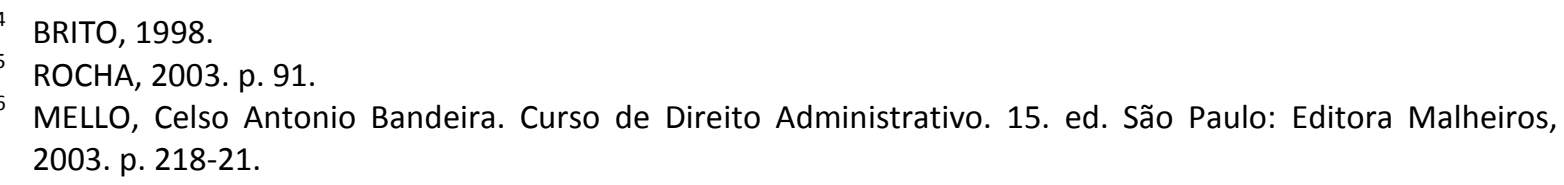

MELLO, Celso Antonio Bandeira. Curso de Direito Administrativo. 15. ed. São Paulo: Editora Malheiros, 2003. p. 218-21. 
9637/98 não é lei nacional, ou seja, sua aplicação não é obrigatória aos Estados e Municípios, mas deve esta ser seguida quando da elaboração das leis regionais. ${ }^{17}$

É criado pelo Plano de Reforma do Estado o título jurídico Organizações Sociais. A concessão deste título serve como meio de certificação, padronização e controle jurídico, além de ser uma forma de diferenciação das pessoas jurídicas. Aquelas que possuem o título desenvolvem atividades buscando o bem comum, enquanto que as demais o fazem para atingir interesses de seus sócios ou associados.

As entidades interessadas em obter este título devem se submeter ao poder discricionário da Administração Pública. Ao receberem referido título, as Organizações Sociais passam a usufruir vantagens econômicas, tais como isenções fiscais e recebimento de recursos públicos, além de poderem estabelecer parcerias com o Poder Público para a execução de suas atividades.

Para receberem o título de Organização Social a pessoa jurídica deve adequar o seu estatuto às previsões legais, ou seja, deve respeitar a universalização do serviço público além de exercer atividades de interesse público assim definidos em lei. Entre as atividades que podem ser objeto das Organizações Sociais destaca-se: defesa e incentivo à cultura; defesa, preservação e conservação do meio ambiente; educação; saúde; pesquisa científica e desenvolvimento tecnológico.

Além disso, a entidade deve preencher alguns requisitos, dentre os quais destacase: ter personalidade jurídica; ter registro de seu ato constitutivo; não ter fins lucrativos; estar em efetivo funcionamento, servir desinteressadamente à coletividade, possuir Conselho de Administração e Diretoria, com participação de representantes da Administração Pública; não remunerar cargos de sua Diretoria; publicar anualmente relatórios financeiros e de execução do contrato de gestão.

Lúcia Valle Figueiredo, defende que a habilitação das Organizações Sociais depende da aprovação do Ministro ou Titular do órgão supervisor correspondente à área de atuação prevista no contrato social da entidade. Essa aprovação é ato discricionário do Poder Público, ou seja há apreciação de juízo de valor no momento da concessão do título. ${ }^{18}$ Para esta interpretação foi delegado excessivo poder ao Executivo e, principalmente, pouco

17 MEIRELLES, Hely Lopes. Direito Administrativo Brasileiro. 29. ed. São Paulo: Malheiros, 2001. p. 366.
18 FIGUEIREDO, 2003. p. 154.

30

Revista de Direito Público, Londrina, v. 1, N. 2, P. 25-40, MAIO/Ago. 2006. 
controle e limite de sua atuação, trazendo discriminação incompatível com a lei, além de violar o princípio da isonomia, da legalidade e do devido processo legal, "importante para o controle das agências no Direito Administrativo". ${ }^{19}$

Ao realizar o contrato de gestão com o Poder Público, a Organização Social passa a ser alvo de controle e fiscalização. Isso se dá porque essa entidade estará desenvolvendo serviços públicos, ou seja atividades de interesse da coletividade, além do que, na maioria das vezes, receberá recursos públicos e utilizará bens e funcionários da Administração Pública. Portanto, nada mais comum do que, como ocorre com o Poder Público, seja o destino dos bens públicos fiscalizado e controlado.

Esse controle pode ser realizado pelo próprio Poder Público, que tem direito e dever de realizar essa fiscalização. Em geral é o órgão ou entidade da Administração Pública que celebrou o contrato com a Organização Social que fica responsável por fiscalizá-la. Esse órgão nomeia uma Comissão de Avaliação, que irá se manifestar sobre o relatório enviado pela Organização Social. O controle consiste no acompanhamento da execução do contrato e está previsto no artigo 8으, § 1ํㅡ, da Lei 9.637/98.

Existe um meio de controle previsto na Lei 9.637/98. O artigo 30 estabelece a criação do Conselho de Administração e dispõe sobre sua composição. O Conselho deverá ser formado por representantes do Poder Público, de entidades da sociedade civil e por associados da própria Organização Social. José Eduardo Sabo Paes diz ser, com isso, mais fácil o controle social, já que há representação e participação de vários segmentos da

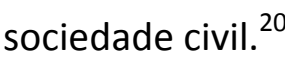

O Tribunal de Contas realiza o julgamento das contas das Organizações Sociais, bem como toma as providências cabíveis no caso de irregularidades informadas pelo Poder Público. Hoje é pacífico o entendimento de que pode o Tribunal de Contas realizar o controle, frente ao parágrafo único do artigo 70 , da Constituição Federal, que foi alterado pela Emenda Constitucional no 19/98: “Prestará contas qualquer pessoa física ou jurídica, pública ou privada, que utiliza, arrecade, guarde, gerencie ou administre dinheiros, bens e valores públicos ou pelos quais a União responda, ou que, em nome desta assuma obrigações de natureza pecuniária".

19 Ibidem.

20 PAES. José Eduardo Sabo. Fundações e Entidades de Interesse Social. 5. ed. Brasília: Brasília Jurídica, 2004. p. 114. 
O cidadão possui legitimidade para fiscalizar as Organizações Sociais usando do instrumento da Ação Popular. Apesar de essas entidades não pertencerem à Administração direta ou indireta e ser este requisito indispensável à propositura da Ação Popular, Silvio Luis da Rocha entende ser este o remédio adequado ao controle popular, baseando-se na amplitude do texto constitucional vigente. ${ }^{21}$

\section{Contrato de gestão}

A parceria entre Administração Pública e Organização Social é realizada através do contrato de gestão que, com base no art. 5ㅇ, Lei 9.637/98, pode ser conceituado como "o instrumento firmado entre o Poder Público e a entidade qualificada como Organização Social, com vistas à formação de parceria entre as partes para fomento e execução de atividades relativas às áreas relacionadas no art. 10."

Hely Lopes Meirelles ao analisar o contrato de gestão o diz como:

o instrumento jurídico básico dessa forma de parceria entre o setor público e o privado. Embora a lei denomine este instrumento de contrato, na verdade trata-se de um acordo operacional entre a Administração e a entidade privada. ${ }^{22}$

Celso Antonio Bandeira de Mello defende que os contratos de gestão:

Seriam, pois, em principio, pura e simplesmente 'contratos administrativos', figura jurídica perfeitamente conhecida. Deveras, aqui nada mais haveria senão como é corrente no Direito Administrativo - um relacionamento de natureza contratual entre o Poder Público e um outro sujeito encartado no universo privado. ${ }^{23}$

Estes contratos são celebrados, em comum acordo entre as partes, tendo de um lado as Organizações Sociais e de outro o Poder Público. Seu objetivo é estabelecer os direitos e deveres de ambas as partes, ou seja, deverá trazer as atribuições, responsabilidades, obrigações e formas de controle para o desempenho destas atividades.

O contrato de gestão possui a natureza jurídica de parceria. Isso porque é uma forma de substituir a relação de hierarquia presente nas relações entre o Poder Público e o

ROCHA, 2003. p.132.

22 MEIRELLES, 2001. p. 366.

23 MELLO, 2003. p. 218. 
particular. Através deste contrato ocorre a contratualização das relações, trazendo ao Estado um comportamento empresarial.

Silvio Luis Ferreira da Rocha diz ter o contrato de gestão a natureza de contrato administrativo degradado, por lhe faltar, "na essência, o reconhecido direito ao equilíbrio econômico-financeiro do administrado." ${ }^{24}$ Explanando que, além de instrumento hábil ao recebimento de recursos públicos, o contrato de gestão pode ser um eficiente meio de controle do desempenho das atividades e da aplicação desses recursos. ${ }^{25}$

Como todo ato emanado pela Administração Pública a elaboração deste contrato de gestão deve observar os seguintes princípios: da legalidade (o contrato deve ter como base uma norma legal específica), da impessoalidade (não pode o contrato conter subjetividades), da moralidade, da publicidade (transparência das atividades administrativas), da economicidade (o contrato deve considerar a racionalização de custos e otimização de resultados).

O contrato deve estabelecer o programa de trabalho que será desenvolvido pela Organização Social, com previsão de metas, prazos de execução, critérios objetivos de avaliação e limites impostos com despesas e remunerações destinadas aos dirigentes e empregados das Organizações Sociais. Pode prever o recebimento de recursos orçamentários e bens públicos. No caso dos bens públicos, estes serão cedidos à Organização Social para o desenvolvimento de sua atividade, sendo dispensada a licitação e mediante permissão de uso. Estes bens podem ser cedidos ou permutados.

É permitida a cessão de servidor a esta Organização Social, neste caso a remuneração do servidor continuará a ser suportada pela administração, não podendo este funcionário receber qualquer valor da entidade, bem como ser renovado, ou seja no caso de aposentadoria, outro não poderá substituí-lo. O quadro de funcionários destas organizações é formado por estes funcionários cedidos pela própria Administração Pública e por funcionários contratados, pelo regime de trabalho previsto na CLT, pela própria organização. Esta contratação é mais comum para suprir as vagas deixadas pelos funcionários cedidos aposentados.

$\begin{array}{ll}24 & \text { ROCHA, 2003. p. } 55 . \\ 25 & \text { Idem. p. } 50 .\end{array}$ 
Deve o contrato indicar as sanções para o caso do descumprimento das atribuições e deveres estabelecidos no próprio contrato. A principal delas é a desqualificação da entidade, ou seja, esta deixa de ser Organização Social. Isto deve ser feito mediante processo administrativo, e com respeito aos princípios da ampla defesa e contraditório. Há a responsabilização solidária e individual dos responsáveis pela Organização Social, além da entrega dos bens e verbas destinados a esta para o desempenho de suas atividades.

Têm-se como exemplos práticos de Organizações Sociais a Associação de Comunicação Educativa Roquette Pinto (ACERP) e Associação Brasileira de Tecnologia de Luz Síncroton (ABTLUS). Estas entidades foram criadas pela Medida Provisória nำ1.591-5. ${ }^{26}$

Para a Administração Pública a principal vantagem trazida pelos contratos de gestão é uma sensível melhoria na prestação dos serviços à comunidade, que são prestados com maior eficiência e menor custo, além de propiciar maior autonomia gerencial a estas organizações. Com isso o Estado deixaria de atuar como executor e passaria a ser fiscalizador e investidor destes serviços. ${ }^{27}$

As Organizações Sociais só poderão prestar serviços não exclusivos, que são aqueles que o Estado atua ao mesmo tempo em que as organizações do setor privado, mas, apesar dessa atuação concorrente, tais serviços são de extrema importância à sociedade, por "envolverem direitos humanos fundamentais, como os da educação e da saúde." ${ }^{28}$

Esta forma de parceria tem gerado muita polêmica. Grande parte da doutrina e da sociedade em geral acredita que estas parcerias contrariam os princípios da Administração. Existem vários exemplos de contratos de gestão, em especial, visando a publicização do serviço de saúde, e em todas as esferas, seja municipal, estadual e federal. Como exemplo, dentre outros, pode-se $\operatorname{citar}^{29}$ :

a) Município de São Paulo: criou o PAS, em 1995, e com isso transferiu suas unidades hospitalares a cooperativas de médicos, esta transferência ocorreu sem licitação.

b) Estado da Bahia: a Lei Estadual 7.027/97 instituiu o "Programa Estadual de Incentivo às Organizações Sociais", que também visa repassar para as Organizações Sociais

26 Organizações Sociais Redesenham o Estado. In Revista do Ministério da Administração Federal e Reforma do Estado, no01, maio /98, pg. 14/21.

27 NÓBREGA. Maílson. In Revista do Ministério da Administração Federal e Reforma do Estado. op cit.

28 GONÇALVES, Wagner. Parecer sobre Terceirização e Parcerias na Saúde Pública. In 29 www.datasus.gov.br/cns/temas/WAGTERC.htm, acessado em 14.03.2005.

Ibidem. 
atividades não exclusivas, tais como a saúde, estas transferências também se deram sem licitação e por meio de contratos de gestão, o que diferencia os dois modelos é que o baiano não permite a cessão de funcionários da Administração para estas organizações.

Sendo a saúde serviço não exclusivo do Estado, é permitido que a iniciativa privada desempenhe atividades a ela relacionadas. Entretanto, conforme o disposto no artigo 199, da Constituição Federal, esse exercício deve ser realizado de forma complementar, ou seja, as entidades privadas podem prestar serviços de saúde, mas deve subsistir o dever do Estado de prestá-los diretamente.

Vale ressaltar que o Ministério da Administração Federal e Reforma do Estado, em artigo publicado na Revista da MARE, considera se tratar o contrato de gestão de instrumento de parceria lícito e diverso da privatização. Já que o contrato é apenas uma permissão dada a certa entidade para prestar certo serviço público, enquanto que na privatização há venda do patrimônio público e autonomia dos compradores. ${ }^{30}$

Por outro lado, é importante destacar a existência das ADINs no 1923-6 e 1943-1, impetradas pelo Conselho Federal da Ordem dos Advogados do Brasil, que questionam a inconstitucionalidade da Lei 9.637/98. Em ambos os casos, como exposto por José Eduardo Sabo Paes, há insurgência contra o artigo 2 que confere excessivo poder ao Executivo de conceder a qualificação de Organização Social, causando violação ao princípio do Estado Democrático de Direito. $^{31}$

Dentre os principais críticos pode-se destacar os seguintes:

\section{a) Wagner Gonçalves}

O Subprocurador Geral da República e Procurador Federal dos Direitos do Cidadão, Wagner Gonçalves" ${ }^{32}$, em seu artigo “Parecer sobre Terceirização e Parcerias na Saúde Pública", censura este modelo de gestão. Sua principal reclamação é que o Estado simplesmente transfere a titularidade de um serviço público ao particular. O ideal seria se somente permitisse que a Organização Social desempenhasse estas atividades, em conjunto

\footnotetext{
30 Organizações Sociais Redesenham o Estado. In Revista do Ministério da Administração Federal e Reforma do Estado, no01, maio /98, pg. 14/21.

31 PAES, 2004, p. 119.

32 GONÇALVES. op. cit.
} 
com o Estado, como forma de melhorar a prestação deste serviço e para aumentar a capacidade de atendimento.

Critica os contratos de gestão porque os mesmos não respeitam as normas de direito público, tanto na formação, já que a contratação se dá sem licitação, violando o artigo 175, da Constituição Federal, quanto na execução, as Organizações Sociais não realizam licitação e nem concurso público. ${ }^{33}$

Afirma ser o objetivo dos contratos de gestão a privatização dos serviços públicos sob a alegação de eficiência, modernidade e eficácia, constituindo uma violentação ao Estado de Direito. E, ainda, que a Lei 9637/98 é inconstitucional por violar a obrigação que o Estado tem de fornecer serviço de saúde para a sociedade, porque, por esta lei, entende-se que as Organizações Sociais tornam-se titulares do serviço público, visando, com isso, "afastar o Estado da prestação de serviços públicos de saúde, transferindo-os totalmente para a iniciativa privada, sob a denominação de Organizações Sociais." ${ }^{34}$

b) Lúcia Valle Figueiredo:

Lúcia Valle Figueiredo ${ }^{35}$ explica que o desenvolvimento das atividades de saúde pelas Organizações Sociais é inconstitucional, porque se tem a noção de que o Estado, ao transferir a titularidade do serviço às Organizações Sociais, pretende não mais desempenhar o serviço de saúde à população. E o Art. 196, da Constituição Federal, prevê ser a saúde, além de direito de todos, dever do Estado. Deve prestá-lo e mesmo quando prestado, concorrentemente, pelo particular, deve fiscalizar esta prestação.

c) Celso Antonio Bandeira de Mello:

Celso Antonio Bandeira de Mello critica o contrato de gestão por considerá-lo inconstitucional. Não por ser este firmado entre a Administração e a Organização Social, mas pela maneira que essa parceria é realizada. Da forma estabelecida pela lei este contrato viola o princípio constitucional da isonomia, ao dispensar a licitação para a escolha da Organização Social a ser contratada, além de conceder excessivo poder discricionário à Administração Pública.

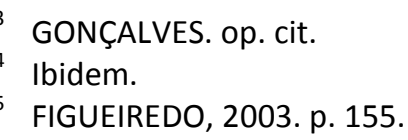


Age de forma equivocada ao não exigir nenhum requisito técnico ou econômico para a escolha da Organização Social, deixando-se totalmente ao critério do Ministro correspondente tal decisão. Celso Antonio Bandeira de Mello considera essa não exigência uma violação a Constituição, já que a Organização Social receberá bens públicos, móveis e imóveis, além de recursos orçamentários e servidores públicos. "36

Outra crítica por ele feita é quanto à delegação de serviço público às Organizações Sociais. Em sua opinião essa delegação deveria ser feita após a realização de licitação, uma vez que essa é a forma empregada nos casos de concessão ou permissão. Além do que o Estado, por meio do contrato de gestão, está tentando se exonerar dos serviços que lhe são exclusivos como a saúde e a educação, previstos na Constituição Federal, artigos 196, 205. ${ }^{37}$ Concluindo que a Organização Social só poderia prestar serviços de forma concorrente ao Estado, sendo que este deve continuar a exercer os encargos impostos pela Constituição. ${ }^{38}$

d) Maria Sylvia Zanello di Pietro:

No mesmo sentido, Maria Sylvia Zanello di Pietro critica tais contratos de gestão. Sua principal condenação consiste no fato de serem essas entidades uma forma usada pelo Estado de prestar o mesmo serviço, sobre as mesmas condições, mesma estrutura e pessoal, mas sem a excessiva burocracia estatal. ${ }^{39}$ Maria Sylvia Zanello di Pietro defende que é evidente a intenção do legislador de usar o contrato de gestão como forma de fugir do regime público. A Organização Social exerce o serviço público que o Estado antes exercia, usando, para tanto, patrimônio, funcionários e bens públicos, com a única diferença de que o regime a ela aplicado é o privado, ou seja as Organizações Sociais não se submetem às chamadas "amarras da Administração Pública." "40

Para esta autora a Lei poderia se tornar constitucional se realizadas as seguintes alterações: realização de licitação para escolha da entidade e submissão aos seus princípios; prova da prévia existência da mesma, com sede, patrimônio e capital próprio, além de outros requisitos exigidos para a constituição válida de uma pessoa jurídica; comprovação de qualificação técnica e idoneidade financeira para gerir patrimônio público; determinação de

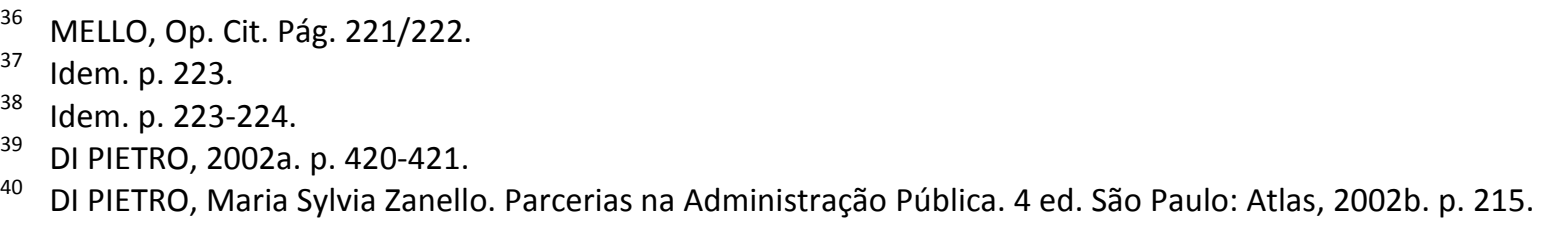


limite salarial, quando use de recursos orçamentários públicos para remunerar seus empregados; prestação de garantia, como exigido nos contratos administrativos. ${ }^{41}$

Maria Sylvia Zanella di Pietro diz serem estes contratos de gestão nada mais do que a privatização do Estado, "sob outra modalidade que não a venda de ações". Isso porque, o órgão que antes exercia a atividade pública é extinto para que a Organização Social, pessoa jurídica de direito privado e não pertencente à Administração direta ou indireta, passe a desempenhar os serviços públicos. ${ }^{42}$

Pode-se extrair que os principais problemas relacionados ao contrato de gestão são: a delegação de serviço público exclusivo do Estado ao particular; a concessão de grande liberdade ao particular e o pouco controle de suas atividades e do destino do patrimônio público que the é atribuído; a discricionariedade do administrador tanto na concessão do título de Organização Social, quanto no contrato de gestão; e a desobediência aos princípios constitucionais norteadores da Administração Pública.

\section{Conclusão}

As opiniões apresentadas são uníssonas com relação ao contrato de gestão. Todas o consideram meio inconstitucional de parceria entre o Estado e a Organização Social, além de destacarem a ausência de licitação, tanto para a escolha da entidade, quanto para essa contratar seus serviços e funcionários, a excessiva liberdade da organização e o excessivo poder discricionário da Administração Pública.

Entende-se que o contrato de gestão é um instrumento importante para o desenvolvimento do Estado Brasileiro, entretanto este utensílio está sendo usado de forma ilegal e, até mesmo, inconstitucional. E conclui-se no sentido de ser necessário e até benéfico ao Poder Público o uso do contrato de gestão em sua atividade, porém tal uso depende de uma adequação à legislação brasileira em vigor, em especial à Constituição Federal, e essa adaptação só virá com maior conhecimento do assunto, debates e alterações legislativas.

41 Idem. p. 216.

42 Idem. p. 213. 


\section{Referências}

BONAVIDES, Paulo. Do Estado Liberal ao Estado Social. 3. ed. Rio de Janeiro: Fundação Getúlio Vargas, 1972.

DALLARI, Dalmo de Abreu. Elementos da Teoria Geral do Estado. 21. ed. São Paulo: Editora Saraiva, 2000.

DI PIETRO, Maria Sylvia Zanello. Direito Administrativo. 14. ed. São Paulo: Editora Atlas, 2002a.

Parcerias na Administração Pública. 4. ed. São Paulo: Editora Atlas, $2002 b$.

FIGUEIREDO, Lúcia Valle. Curso de Direito Administrativo. 7. ed. São Paulo: Malheiros, 2003.

GONÇALVES, Wagner. Parecer sobre Terceirização e Parcerias na Saúde Pública. Disponível em: <www.datasus.gov.br/cns/temas/WAGTERC.htm>. Acesso em: 14 mar. 2005.

MEIRELLES, Hely Lopes. Direito Administrativo Brasileiro. 29. ed. São Paulo: Editora Malheiros, 2001.

MELLO, Celso Antonio Bandeira. Curso de Direito Administrativo. 15. ed. São Paulo: Malheiros, 2003.

MINISTÉRIO da Administração e Reforma do Estado. Cadernos MARE da Reforma do Estado, v. 2. p. 35.

ORGANIZAÇÕES Sociais Redesenham o Estado. Revista do Ministério da Administração Federal e Reforma do Estado, n. 1, p. 14-21, maio 1998.

PAES, José Eduardo Sabo. Fundações e Entidades de Interesse Social. 5. ed. Brasília: Editora UnB, 2004.

REVISTA DA FAE, Curitiba, v. 6, n. 1, p. 81-88, jan./abr. 2003.

ROCHA, Silvio Luis da. Terceiro Setor. São Paulo: Editora Malheiros, 2003.

SORMAN, Guy. O Estado Mínimo. Rio de Janeiro: Editora Instituto Liberal, 1988. 
